\title{
Power Factor Improvement using Bidirectional Switched Mode Converter
}

\author{
Nimmya Mathew \\ Department of EEE \\ Toc H Institute of Science and Technology \\ Ernakulam, India
}

\author{
Anjumol C. S \\ Department of EEE \\ Toc H Institute of Science and Technology \\ Ernakulam, India
}

\begin{abstract}
This paper presents a new ideology of bidirectional switched mode converter which allows bidirectional power handling capability. A bidirectional AC/DC converter is proposed to improve power factor and to reduce the losses. DC power based applications like space, telecommunications and computer systems are using the bidirectional converters as it is compact, smaller and efficient. A single converter unit is necessary instead of two uni-directional converters since it is capable of bilateral power flow. The system consists of a converter and an inverter which converts AC supply to dc supply and vice versa. MOSFET's are used in this paper instead of IGBT as it has advantages of higher commutation speed and greater efficiency during operation at low voltages.
\end{abstract}

Index Terms-Power factor, switched mode converters

\section{INTRODUCTION}

Both converters and inverters are a vital part in every alternating and direct voltage conversions. Low voltage application such as charging batteries, PV industry and home appliances requires DC voltage whereas industrial system, and other large voltage application requires $\mathrm{AC}$ voltage. In recent years, different conversion techniques have been developed as the demand for industrial motor drives increasing day by day. The conventional AC/DC rectification is not satisfactory. Hence, that system approaches a method using a full wave bridge accommodated with a bulk capacitor is unsuitable because of unwanted input current harmonics [1]. Harmonic emission techniques are passive filtering, power factor correction, and active filtering [2-11]. Due to the large capacitor bank the size, weight and cost of converter equipment will be high. To dissipate the regenerative energy, braking resistors can be used but it reduces the overall efficiency of the drive system. To avoid the use of link capacitor and braking resistor a new concept implemented where the regenerative energy can be absorbed by the supply [7-8]. A bidirectional converter introduced which combines both converters and inverters. Bidirectional converter topology usually consists of four fully controlled switches. The new converter allows the stored energy in loads regenerate back to the supply. This feature leading to not only in the reduction in size, but also an increase in overall efficiency in the system. Power factor improvement using the bidirectional feature together with the switched mode converter can be employed in industrial motor drive systems. Bidirectional flow capability along with several ideologies were developed using

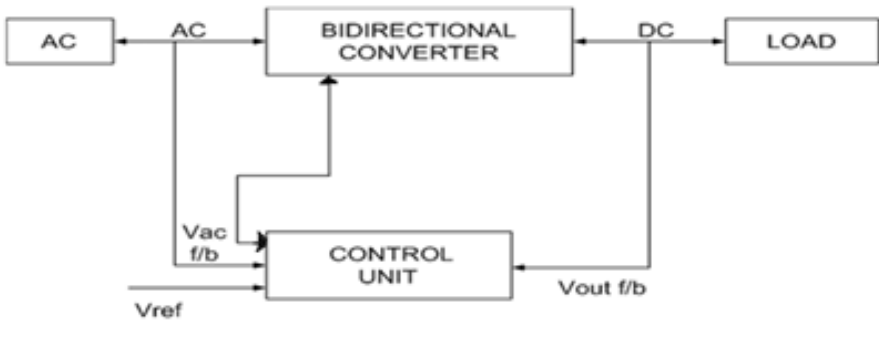

Fig. 1. Block diagram of proposed system

SCR, IGBT and GTO [7-8]. SCR has advantages such as low cost and highly robust as well as it commutate naturally. But SCRs are not preferable since it is unidirectional. In this paper, bidirectional converter accompanying MOSFET as switches are employed. MOSFET has advantages of higher commutation speed, and greater efficiency when compared to the IGBT. There are many drawbacks in the conventional system. Conventional converter has additional diodes and switches in ac to dc conversion which increases losses. In DC to AC conversion additional switch S2 needed to reverse supply. Conduction losses are more due to the additional switches. Less efficient circuit due to the presence of these additional components. The proposed converter system can be operated with unity power factor for bidirectional power flow conditions and thus can reduce harmonic pollution of ac drives. The direction of the current flow in the inductor is the same under both motoring and regenerating conditions. A particular way of switching implemented which requires lesser number f switches and thus it reduces overall switching losses and increases its efficiency. Power factor correction in both power flow directions can be achieved using a simple control method. In AC to DC, conversion stage boost converter developed using inductor, capacitor and switch. Gate PWM pulses of variable duty cycle are given to the switches for proper commutation. In this paper bidirectional converter modified and practically demonstrated. 


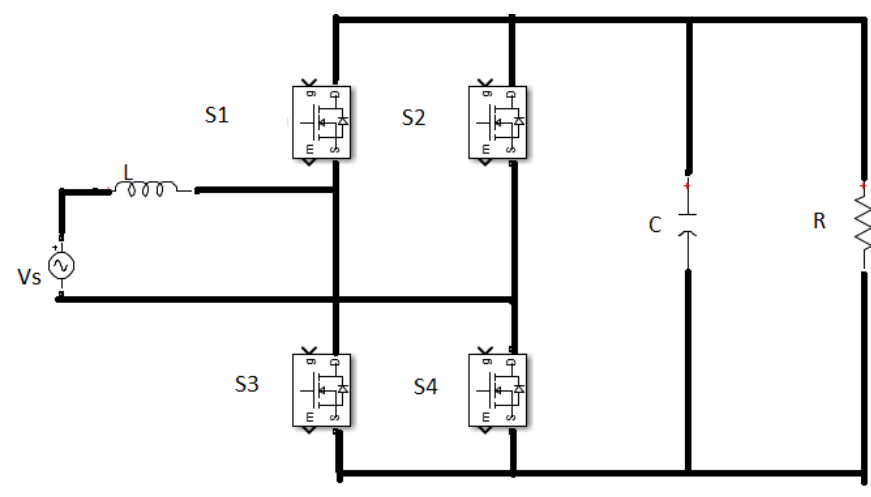

Fig. 2. Circuit diagram of proposed system

\section{PRINCIPLES OF OPERATION}

Fig. 1 shows the block diagram of the proposed bidirectional switched mode converter.The modified system consists of four fully controlled MOSFETs ( $\mathrm{S} 1, \mathrm{~S} 2, \mathrm{~S} 3, \mathrm{~S} 4)$, a series inductor, a capacitor to reduce the voltage ripple and resistive load. Modes of operation can be divided $n$ to two based on the status of converter switch 1) Motoring mode 2) Regenerating mode. Fig. 2 shows the circuit diagram of the proposed power factor improvement using bidiectional switched mode converter.Motoring mode or regenerataing mode selected based on the application. Modes of operation determined from the signal generated by the controller.

\section{A. Motoring mode}

The input voltage is stepped down using transformer for conversion and it gets rectified to produce DC output. Switches S1 and S2 turned on during positive half cycle. S3 and S4 turned on during negative half cycle. MOSFET with the body diodes perform boost operation and power factor achieved by modifying output voltage w.r.t current. Inductor get charged and discharged during switching operation for boosting. [3]In the positive half cycle, AC-DC conversion takes place S1 and S2 turned on then inductor get charged. Current flow through voltage source Vs, Inductor L, S1 ,S2 . When switch turned off inductor get discharged through body diode D1 of switch s1, load and body diode D3. In the negative half cycle S3 and S4 turned on inductor get charged through the switches. When switches turned off[6] current flow through D2,load, D4 and source. PWM gate pulse generated by the control unit and thus inductor current follwed the rectified form of input voltage. Feedback current and reference current compared through out the operation.

\section{B. Regenerating mode}

MOSFET along with body diodes perform DC to AC conversion. In regenerating mode (DC to AC) S1,S2,S3,S4 turned on diagonally as similar to that in existing system during positive and negative cycles accordingly.During positive half cycle from load, S1, inductor, source and S4.During negative half cycle $\mathrm{S} 2$ and $\mathrm{S} 3$ turned on accordingly. S1,S2,S3,S4 are switched in anti-phase with the operation in motoring mode.
Demands for eco-friendly vehicles are increasing day by day. Based on electricity many vehicles have been developed and their leading feature is the ability to recover significant amounts of barking energy. fuel economy get improved by implementing such vehicles. So the basic idea focused during acceleration and reused that stored energy without additional sources.After having studied and understood Bidirectional ACDC power converter with power factor correction, the circuit design can be addressed.

\section{DESIGN CONSIDERATION}

The task of designing Bidirectional AC-DC power converter with power factor correction involves certain criteria. The selection of inductance value for bi-directional AC to DC power converter circuit is based on current ripple and maximum current in the inductor. The value of $\mathrm{C}$ is determined by considering the maximum ripple voltage on the $V_{d c}$ is the equivalent circuit in motoring mode Parameters Of Bidirectional AC-DC power converter with power factor correction $V_{i}=12 \mathrm{~V}$

$f_{s}=40 \mathrm{kHz}$

$I_{s}=25 \mu \mathrm{s}$

$\mathrm{i}_{\text {ripple }}=10 \%$ of $I_{s}$

$V_{0}=24 \mathrm{~V}$

Value of inductor $L_{(2,3)}$ is,

$$
L_{\text {min }}=\frac{M V_{m} T_{s}}{4 I_{\text {ripple }}}
$$

$$
\begin{gathered}
i_{s}=\frac{500}{12 \sqrt{2}}=58.7 \mathrm{~A} \\
L_{\min }=1.6 \mathrm{mH}
\end{gathered}
$$

\section{Simulation Results}

The converter has been tested with resistive load. The computer aided performance of A bidirecional AC-DC power converter with power factor correction is simulated using Matlab Simulink using Simscape toolbox and discrete time sampling. In ac to dc conversion boosting occurs hence output voltage of $24 \mathrm{~V}$ obtained for the given input voltage $12 \mathrm{~V}$. Simulated the dc to ac conversion. 16.7 V is obtained as output for the given $24 \mathrm{~V}$ input voltage. The matlab simulation of the converter is done using these parameters. The matlab simulation of the system with $R=100 \Omega$ is simulated. Current waveforms of AC-DC and DC-AC conveter are shown in Fig.3. and Fig.4.respectively.

\section{CONCLUSION}

The bidirectional AC/DC power converter is studied, implemented and the design performance is validated with simulated results. It has the ad- vantages of the proposed converter which can be operated with unity power factor for bi-directional power ow conditions. Thus, it can reduce source side current harmonic content and the power factor corrected AC/DC converter uses a phase controlled thyristor rectifier. This converter is robust and low cost. Since the converter has bidirectional power ow capability, the energy storage requirement and the 


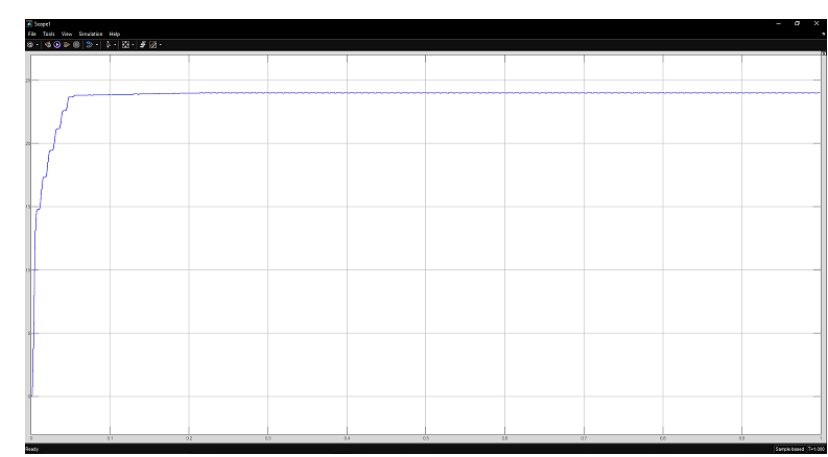

Fig. 3. Output voltage waveform of the converter

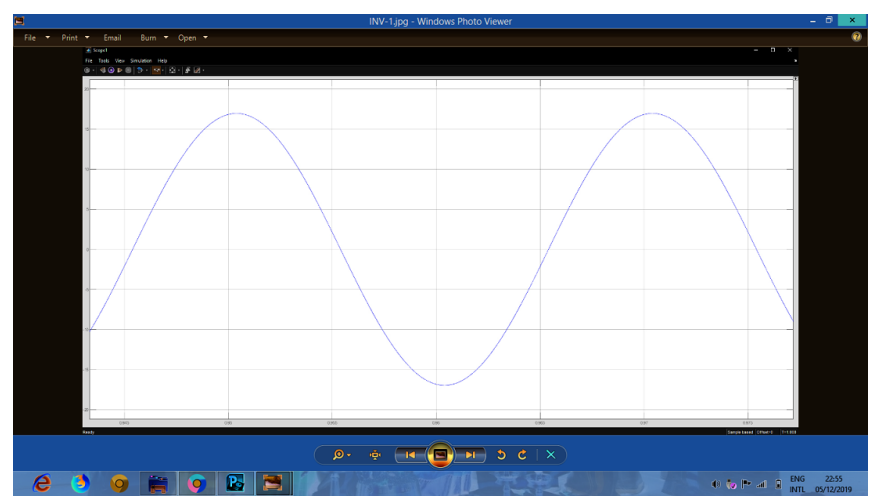

Fig. 4. output voltage diagram of DC-AC converter

size of the dc link capacitor is reduced. The direction of the current flow in the inductor is same under both motoring and regenerating mode. This proposed model makes the current control simple. The proposed operation provides a low cost and reliable operation for $\mathrm{AC}$ motor drive systems that require frequent regeneration. The control strategy adopted in the demonstration is simple and commonly used in current controlled power converters. The power factor correction feature of the new converter operation therefore does not require a complicated control system.

\section{REFERENCES}

[1] S. C. Kaishian, D. C. Pixler, T. A. Roebke, S. D. Day, and W. K. Siebert,Cooling of electrical components with split-flow closed-end devices,May 2007, US Patent 7 , 212,406

[2] L. Gebhardt and B. Richter, Surge arrester application of MV Capacitor banks to mitigate problems of switching restrikes in Int. Conf. on Electricity Distribution, Vienna, 2007.

[3] M. Morimoto, K. Oshitani, K. Sumito, and S. Okuma, New single phase unity power factor PWM converter inverter system in Proc IEEE PESC. vol. 30, no. 2, pp.585-589, 2015

[4] R. K. Varma, V. Khadkikar and R. Seethapathy, Night-Time Application of PV Solar Farm as STATCOM to Regulate Grid Voltage in IEEE Transactions on Energy Conversion, vol. 24, no. 4, pp. 983-985, 2009.

[5] A. Surendran and A. S Mohan, A case study on PV STATCOM with different controls for increasing grid power transmission limits during night and day International Journal of Scientific Engineering Research vol. 7, no. 4, pp. 487-492, 2016

[6] R. M. Davis and C. G. Alexander, A bidirectional AC-DC power converter for fixed polarity de loads in Proc IEE PEVD,vol. 1, no. 9, pp. 142-145, 2012.
[7] P. Weeler, J. Clare, and M. Sumner, The integration of a bidirectional rectifier and a voltage fed inverter in an optimized high performance variable speed ac motor drive system in Proc.IEE PEVD vol. 16, no. 1, pp. 396-400,2011

[8] A. Pasricha, Crow, M.L.A method of improving transformer overloading beyond nameplate rating North American Power Symposium (NAPS), Charlotte, NC, USA, 2015

[9] T. Kamakawaji, T. Shioiri, T. Funahashi, Y. Satoh, E. Kaneko and I. Oshima, An investigation into major factors in shunt capacitor switching performances by vacuum CBs with copper chromium contacts IEEE Trans Power Deliv, vol. 8, no. 4, pp. 1789-95, 2014

[10] R. M. Mathur and R. K.Varma, Thyristor- Based FACTS controllers for Electrical Transmission systems, Newyork: Wiley IEEE press , 2002. 